Rapport - Société canadienne d'histoire de l'Église catholique

\title{
Autour de la paroisse du Sacré-Coeur de Toronto
}

\section{Benoît Jobin}

Volume 26, 1959

URI : https://id.erudit.org/iderudit/1007415ar

DOI : https://doi.org/10.7202/1007415ar

Aller au sommaire du numéro

Éditeur(s)

La Société canadienne d'histoire de l'Église catholique

ISSN

0318-6148 (imprimé)

1927-7075 (numérique)

Découvrir la revue

Citer cet article

Jobin, B. (1959). Autour de la paroisse du Sacré-Coeur de Toronto. Rapport -

Société canadienne d'histoire de l'Église catholique, 26, 57-62.

https://doi.org/10.7202/1007415ar

Tous droits réservés @ La Société canadienne d'histoire de l'Église catholique, 1960
Ce document est protégé par la loi sur le droit d'auteur. L'utilisation des services d’Érudit (y compris la reproduction) est assujettie à sa politique d'utilisation que vous pouvez consulter en ligne.

https://apropos.erudit.org/fr/usagers/politique-dutilisation/ 


\section{Autour de la paroisse du Sacré-Coeur de Toronto}

Les historiens nous disent qu'écrire l'histoire d'une génération encore vivante est une tâche difficile et délicate. Les conséquences des actes publics se développent tranquillement. Les témoins demeurent avec leurs propres impressions et récollections des différentes scènes, même après que les acteurs ne sont plus là.

Tracer l'histoire de la paroisse du Sacré-Cour de Toronto est donc aussi une chose délicate parce qu'il y a encore des témoins qui ont eu connaissance de ses débuts.

Si nous revenons en arrière, l'histoire nous enseigne que la liberté de l'Eglise avait été garantie par le Traité de Paris et l'Acte de Québec. Mais cette liberté n'a été reconnue qu'après la guerre de 1812. Durant ces années et jusqu'en 1820 les soins religieux des Canadiens et des immigrants étaient donc confiés à l'évêque de Québec. Bien des années avant la fondation de la paroisse française de Toronto, il y avait donc des prêtres de langue française qui parcouraient tout le diocèse et venaient en aide aux catholiques de langue française et aux autres.

Durant le même temps il n'y avait pas un établissement, pas un poste de commerce et pas un fort sans qu'il y ait un prêtre en charge; ce n'était plus les Pères Jésuites ou les Pères Franciscains qui se sont tant dépensés au début de la colonie et qui voyaient aux besoins de ces gens, mais des prêtres séculiers du diocèse de Québec.

Ce n'était plus les Indiens qui formaient la communauté paroissiale ou la mission, mais les immigrants écossais, irlandais et les descendants des anciens colons français.

Tant que le Canada fut français les missions situées à l'ouest du diocèse de Québec étaient florissantes; après la cession du Canada à l'Angleterre, ces missions végétèrent et même plusieurs disparurent complètement.

Le temps est donc venu pour que l'Eglise du Haut-Canada commence une autre époque de son histoire. Elle avait toujours fait partie du diocèse de Québec; maintenant l'Eglise du Haut-Canada devait se suffire à elle-même et prendre sa place dans le grand cercle des sièges épiscopaux et recevoir ses directives de Saint-Pierre de Rome, mère et maîtresse des églises.

Cette division du diocèse de Québec était un projet que $\mathrm{M}^{\mathrm{gr}}$ Plessis contemplait depuis le début de son épiscopat. Toutefois ce n'est que le 12 janvier 1819 que l'abbé MacDonell était nommé par Sa Sainteté Pie VII, évêque de Regina et vicaire apostolique du Haut-Canada; mais il ne fut consacré que deux ans plus tard par $\mathrm{M}^{\mathrm{gr}}$ Plessis dans la chapelle du Couvent des Ursulines à Québec, le 31 décembre 1820 . 
En 1827, Son Exc. $\mathrm{M}^{\mathrm{gr}}$ MacDonell, évêque de Kingston, entreprit de visiter son immense diocèse. En arrivant à York, aujourd'hui Toronto, $\mathbf{M}^{\mathrm{gr}}$ MacDonell trouva une poignée de catholiques qui étaient dirigés par l'abbé Crawley, curé de l'église Saint-Paul, la seule place où le culte catholique était pratiqué dans York.

Le Haut-Canada devenait de plus en plus populeux et $\mathrm{M}^{\mathrm{gr}}$ Gaulin, de Kingston, demanda à Rome de subdiviser son diocèse. Le 17 décembre 1841, le pape Grégoire XVI permettait la division du diocèse et nommait ce jour même $\mathbf{M}^{\mathrm{gr}}$ Michael Power, né à Sainte-Martine, Québec, et vicaire général du diocèse de Montréal, comme premier évêque du nouveau diocèse. Rome avait laissé à la discrétion de l'évêque élu le choix de sa ville épiscopale. Son Excellence $\mathbf{M}^{\mathrm{gr}}$ Power choisit Toronto comme siège épiscopal. Cette ville n'était pas seulement la plus populeuse de la province dans le temps, mais $\mathrm{M}^{\mathrm{gr}}$ Power reconnaissait qu'elle serait une grande métropole dans le futur et un centre influent, culturel et artistique.

Les historiens nous disent que Toronto a été privilégiée en ayant comme premier évêque $\mathrm{M}^{\mathrm{gr}}$ Power. "Nous trouvions, nous dit-on, dans $\mathrm{M}^{\mathrm{gr}}$ Power, un homme de prières doué d'une âme de missionnaire, de la patience et du courage d'un martyr. "A la mort de Son Excellence $\mathrm{M}^{\mathrm{gr}}$ Power, un évêque français nommé à Toronto.

Le diocèse continua de se développer sous les directives de $\mathrm{M}^{\mathrm{gr}}$ de Charbonnel qui termina la cathédrale actuelle, fit venir les Frères des Ecoles Chrétiennes, les Pères Basiliens de France et les Sœurs de SaintJoseph de Philadelphie. Une question chère au cœur de $\mathrm{M}^{\mathrm{gr}}$ de Charbonnel était les écoles séparées. Sa première année d'épiscopat terminée, il écrivait à Rome : "Je n'entends rien négliger pour assurer le succès de cette entreprise." Lorsque $\mathrm{M}^{\mathrm{gr}}$ de Charbonnel quitta Toronto pour se retirer en France, il avait accompli un grand travail apostolique.

Même si la religion catholique avait fait de grands progrès dans le Haut-Canada, sous les directives des deux premiers évếques de Toronto, les conditions dans la province n'étaient pas satisfaisantes. Le nombre de prêtres était insuffisant; les quelques églises établies étaient pratiquement toutes des structures temporaires. Dans bien des milieux, il n'y avait que quelques catholiques, tellement dispersés et pauvres, qu'il était impossible de construire la plus humble des chapelles.

Tout d'abord coadjuteur de $\mathbf{M}^{\mathrm{gr}}$ de Charbonnel, $\mathrm{M}^{\mathrm{gr}}$ Lynch lui avait succédé, le 20 novembre 1859 , et le diocèse de Toronto et toute la province de l'Ontario d'ailleurs, faisait encore partie de la province ecclésiastique de Québec. Le progrès de l'Eglise en Ontario prouva la nécessité d'ériger une province ecclésiastique ontarienne et $\mathrm{M}^{\mathrm{gr}}$ Lynch fut désigné comme premier archevêque de Toronto. Sous son égide le diocèse connut un épanouissement pratiquement inconcevable.

Parmi le grand nombre de paroisses érigées sous le règne de $\mathrm{M}^{\mathrm{gr}}$ Lynch, on compte la paroisse du Sacré-Cour; elle était de structure différente de toutes les autres du côté linguistique et fut érigée pour les catholiques de langue française de Toronto. 
Depuis que le Haut-Canada était un diocèse et surtout lorsqu'il fut érigé en province ecclésiastique, il n'y avait plus de prêtres du Québec dans le diocèse de Toronto; toutefois il y avait des Pères Basiliens qui pouvaient aider les catholiques de langue française.

Il y a toujours eu des catholiques d'expression française à Toronto. Aux environs de 1779 il y avait un assez bon contingent de Français dans le Comté de York. Le Dr Scadding, dans son livre Toronto of Old, nous en parle. "La France, dit-il, dans ces années avait beaucoup de difficultés et plusieurs Français avaient immigré en Angleterre, et après la Révolution plusieurs vinrent s'établir au Canada et même dans le Comté de York, et depuis, même si le grand nombre était retourné, il $y$ avait toujours eu quelques familles d'expression française dans l'Ontario. »

Pendant plusieurs années les Pères Basiliens réunirent plusieurs familles françaises dans la chapelle de leur collège et après avoir récité quelques prières, ils leur prêchaient en français; mais ceux qui avaient besoin d'attention spéciale demeuraient éloignés de ces réunions religieuses.

C'est en mai 1887, qu'on a eu l'idée de demander une paroisse française. Le Père Defeanse, rédemptoriste, prêchait une retraite aux Canadiens français dans l'église Saint-Patrice et voyant qu'ils étaient en nombre considérable leur conseilla fortement de s'adresser à $M^{\mathrm{gr}}$ Lynch pour s'ériger en paroisse et obtenir un prêtre de leur langue.

$M^{\text {gr }}$ Lynch acquiesça à leur demande après avoir exigé certaines garanties. Sa grandeur écrivit à $\mathrm{M}^{\mathrm{gr}}$ Fabre, de Montréal, et le supplia de lui envoyer un prêtre canadien-français.

Nous lisons dans les notes historiques de la paroisse que le jeune vicaire du Sacré-Cœur de Montréal, l'abbé Philippe Lamarche, homme fort et robuste et doublé d'une grande piété fut choisi pour ce poste important qu'il occupa sans répit jusqu'à sa mort. Le 24 juin 1887, il arrivait à Toronto où les délégués de la nouvelle paroisse lui firent une cordiale réception à la gare et le conduisirent au Palais Saint-Michel où il demeura quinze mois. Il fut bien accueilli à l'archevêché et la chapelle Saint-Vincent, aujourd'hui connue sous le nom de «St. John's Chapel ", fut mise à la disposition de la nouvelle paroisse moyennant une contribution de $\$ 2.00$ par semaine.

A l'arrivée de l'abbé Philippe Lamarche, les annales diocésaines et paroissiales nous apprennent qu'il y avait 130 familles et que le nombre de familles françaises augmentant de plus en plus, le curé, de l'avis du comité paroissial, acheta sur la rue King, par l'entremise de M. Gendron, une église presbytérienne, au coût de $\$ 12,000.00$, qui fut restaurée et ouverte au culte, le 7 octobre 1888. La première messe fut chantée par le curé de la paroisse. La bénédiction solennelle fut donnée par le vicaire général de l'archidiocèse de Toronto, $M$. l'abbé Laurent et le sermon prêché par le Père Nolin, o.m.i.

A partir de ce jour M. le curé Lamarche établit ses quartiers généraux sur la rue King; et nous lisons dans les archives de la 
paroisse que, du consentement de toute la population française, le SacréCœur de Jésus fut choisi comme titulaire de la nouvelle église.

Un fait dont la jeune paroisse pouvait s'enorgueillir est que le 9 octobre 1887, lorsque son Eminence le cardinal Taschereau vint à Toronto pour la bénédiction de la pierre angulaire de la nouvelle église Saint-Paul, le premier Prince canadien de l'Eglise visita les catholiques de langue française. Il implora la bénédiction de Dieu sur ce groupe pour qu'il soit uni et pour le succès de la paroisse. Comme l'avenir devait le justifier cette bénédiction produisit beaucoup de fruits sous les soins spirituels du dévoué curé de la paroisse du Sacré-Cœur.

Une paroisse sans école n'est pas une paroisse proprement dite; aussi le premier soin du jeune curé fut de doter sa paroisse d'une école convenable. Dans l'histoire de la paroisse nous lisons : "Mais on se demandait où prendre les fonds nécessaires pour la construction d'une école? " La nouvelle paroisse avait bien son église, mais elle n'avait pas encore de presbytère et elle voulait une école. La question fut tranchée. On s'occupera douze ans plus tard du presbytère et on fit la classe huit ans dans le sous-sol de l'église. Dans les années à venir, on préleva la somme d'argent nécessaire pour l'achat d'un terrain et en 1896 le « Separate School Board 》 bâtit le premier étage de l'école.

Le 21 décembre 1924, le curé fondateur, l'abbé Philippe Lamarche, qui s'était dépensé sans compter, atteint de l'anémie pernicieuse qui le poursuivait depuis dix-huit mois, mourait au milieu des siens après un court séjour à l'hôpital Saint-Michel, âgé de 71 ans. L'oraison funèbre fut prononcée par l'abbé Barcelo " who spoke eloquently in French regarding the devoted life and work of the deceased priest, whose name was a household word in the eastern part of the city and whose charity was not circumscribed by creed or belief $»$, nous dit le quotidien The Star de Toronto. Une autre page de l'histoire de l'Eglise, à Toronto, était terminée.

A la mort de l'abbé Philippe Lamarche, la paroisse fut administrée par l'abbé Edouard Lamarche, vicaire et neveu du défunt. Comme son oncle, l'abbé Edouard Lamarche acquiesça à la demande qu'on lui avait faite de venir à l'aide des catholiques d'expression française à Toronto. Le 10 juin 1925, il était nommé curé de la paroisse du SacréCœur, paroisse qu'il dirige encore aujourd'hui.

Aujourd'hui le diocèse de Toronto compte plusieurs paroisses où la prédication se fait dans une autre langue que l'anglais puisque le dimanche l'Evangile catholique est lu, dans cette ville, en vingt-sept langues différentes, mais la paroisse du Sacré-Cœur joue toujours un rôle unique, servir les catholiques de langue française qui demeurent dans tous les quartiers de la ville et des quelques centaines qui formaient à l'origine la paroisse, nous en comptons aujourd'hui plusieurs milliers.

Sous la direction de M. l'abbé Edouard Lamarche les annales paroissiales se sont enrichies de dates très mémorables.

L'Eglise sur la rue King était trop petite, il fallait donc construire plus grand et dans un quartier plus accessible aux paroissiens. M. le curé 
acheta les terrains à l'angle des rues Sherbourne et Carlton et, en 1937, l'église actuelle était construite et en 1951 elle était agrandie.

L'école du Sacré-Cœur, dirigée par les Sœurs de Saint-Joseph de Toronto et connue sous le nom de a French School » parce qu'on y parlait français, était toujours située sur la rue Sackville près de la petite église. En septembre 1940, une maîtresse laïque, Mlle Berthe Castonguay, se joignit aux religieuses de Saint-Joseph et elle commença l'école bilingue, telle que nous la connaissons aujourd'hui. Mlle Castonguay, comme pionnière de l'école bilingue à Toronto mérite donc une mention honorable dans le développement de la paroisse.

Le 3 septembre 1943, les religieuses de la Congrégation Notre-Dame de Montréal prenaient la direction de l'école du Sacré-Cœur et le 3 décembre 1948, les portes d'une nouvelle école s'ouvraient; cette école, située près de l'église actuelle, offre des locaux bien aménagés et modernes. Aujourd'hui nous comptons à l'école 490 élèves, 4 religieuses, 1 professeur et 9 institutrices !

Lorsque les élèves terminaient au Sacré-Cœur, plusieurs désirant continuer leurs études se dirigeaient dans des écoles Secondaires protestantes ce qui était un grand danger pour leur foi. Mère Sainte-MarieFélicien, première directrice de l'école sous la direction des Sœurs de la Congrégation eut l'ingénieuse idée de préparer le terrain pour une école Secondaire bilingue. Cette école fit ses débuts en septembre 1950 avec une classe, la $9^{\circ}$ année qui était enseignée à l'école du Sacré-Cœur; l'année suivante les Religieuses louèrent un local pour recevoir les élèves de $9^{\circ}$ et $10^{\circ}$, et en juillet 1952 , elles acquéraient une résidence à 157, rue Saint-George. Cette maison fut aménagée pour recevoir les élèves en septembre. Cette école secondaire porte le nom de la «Villa Marguerite-Bourgeoys » et, en février 1953, lorsque Son Eminence le cardinal McGuigan bénissait cette école, dans son allocution elle remercia les Religieuses pour la fondation de cette école et leur dit : "Vous commencez d'une manière aussi humble que Marguerite Bourgeoys lorsqu'elle fonda votre communauté à Montréal; je vous souhaite autant de succès dans cette entreprise comme Marguerite Bourgeoys en a eu dans les siennes. "Cette école Secondaire bilingue reçoit non seulement les élèves provenant de familles d'expression française, mais aussi de familles anglaises. Les souhaits de son Eminence ont porté chance, puisqu'au début de septembre 1952, la Villa comptait 27 élèves et aujourd'hui elle en compte 76; faute de locaux les Religieuses ont dû refuser plusieurs élèves en septembre dernier.

Les écoles primaire et secondaire bilingues jouent un rôle très important dans la vie spirituelle de nos fidèles et elles sont uniques dans leur genre. Même si nous avons plusieurs paroisses de différentes langues dans la ville reine, seule la paroisse catholique française a une école où la langue maternelle des jeunes fidèles est enseignée.

Tout ce grand travail d'organisation, de développement à la gloire de l'Eglise se fit sous la direction de l'abbé Edouard Lamarche qui, en décembre 1954, était honoré du titre de prélat domestique de la maison de Sa Sainteté. $M^{\text {gr }}$ Lamarche a accepté cet insigne honneur 
avec beaucoup d'humilité, mais il a voulu qu'il rejaillît non seulement sur lui, mais sur toute la paroisse, sur les pionniers et les paroissiens d'hier comme ceux d'aujourd'hui, qui sont les piliers de la vie catholique française à Toronto.

Depuis 1945, le contingent de gens d'expression française est très grand. En plus des Québecois, des Acadiens, des Franco-Ontariens, nous avons beaucoup d'Européens qui viennent s'établir à Toronto. On arrive de la France, de la Belgique, de la Suisse et on a recours aux prêtres de la paroisse pour trouver du travail, un logis et les aider à s'adapter à leur pays d'adoption. Ce travail se fait en coopération avec les différents clubs sociaux.

Au début du diocèse du Haut-Canada les prêtres étaient considérés comme missionnaires et aujourd'hui le prêtre à la paroisse du SacréCour est un missionnaire, un missionnaire moderne, par rapport à l'étendue qu'il doit couvrir, c'est-à-dire toute la ville de Toronto, pour administrer les sacrements, entrer en contact avec le plus grand nombre possible de catholiques d'expression française, et visiter tous les hôpitaux qui reçoivent des malades de langue française, non seulement de Toronto, mais de toute la province.

Les associations religieuses et sociales se multiplient et les prêtres de la paroisse s'efforcent d'être partout afin de pouvoir continuer d'inculquer les principes moraux et chrétiens qui aident à devenir un meilleur catholique et bon citoyen.

Le travail des prêtres est secondé par un grand nombre d'hommes et de femmes convaincus de leurs obligations religieuses et sociales et qui ne regardent ni le temps, ni le travail pour aider les autres à connaître l'Eglise, et par les postes importants qu'ils occupent, font la gloire de la paroisse.

Et pour terminer, permettez-moi de citer un paragraphe des notes historiques de la paroisse qui était bien vrai il y a trente ans et qui l'est encore aujourd'hui : "La paroisse du Sacré-Cœur, par son église, par son école à formation catholique et française, par ses cercles et ses différentes organisations est réellement le centre de la vie française à Toronto et par son rôle social elle s'impose à l'admiration de tous. s

\author{
Benoît JobIN, ptre \\ Paroisse du Sacré-Caur, Toronto, Ont.
}

